\title{
G8 Summit: sorting out the supplicants
}

Published at www.cmaj.ca on June 24

I nternational aid groups await the June 25-26 G8 Summit in Huntsville, Ontario, with expectations for billions - maybe even tens of billions - of dollars in new funding for maternal and child health programs in the world's poorest countries.

But just who should get the money, and how it should be spent, is a matter of hot debate among maternal and child health advocates.

While several major funds have requested large earmarks, some analysts want the money to go directly toward national health care budgets in countries with high child and maternal mortality. Others suggest the funds themselves need to focus their efforts on improving primary care.

The world's major aid organizations specializing in health care - including the World Bank, the Global Fund to Fight AIDS, Tuberculosis and Malaria, and the Global Alliance for Vaccine Initiatives - have all vigorously signalled to Ottawa that they are hungry for substantial new contributions.

Scores of smaller, specialized groups that deliver health programs in countries with high levels of child and maternal mortality are equally hopeful the G8 leaders will dramatically escalate their funding. In the most optimistic scenario, the G8 nations will commit \$24 billion at the Muskoka summit, says Garth Luke, senior government relations researcher for World Vision Australia.

Thus far, the only firm commitment is a $\$ 1$-billion, five-year pledge from Canada but "if the other G8 countries gave at the same level as Canada, it would reach \$24 billion," Luke notes. But he predicts some countries will view the event as a preliminary to the gathering of over 100 nations in New York City in September for a special review summit on the millennium development goals, where it's hoped the \$24 billion can be bumped up to $\$ 30$ billion.

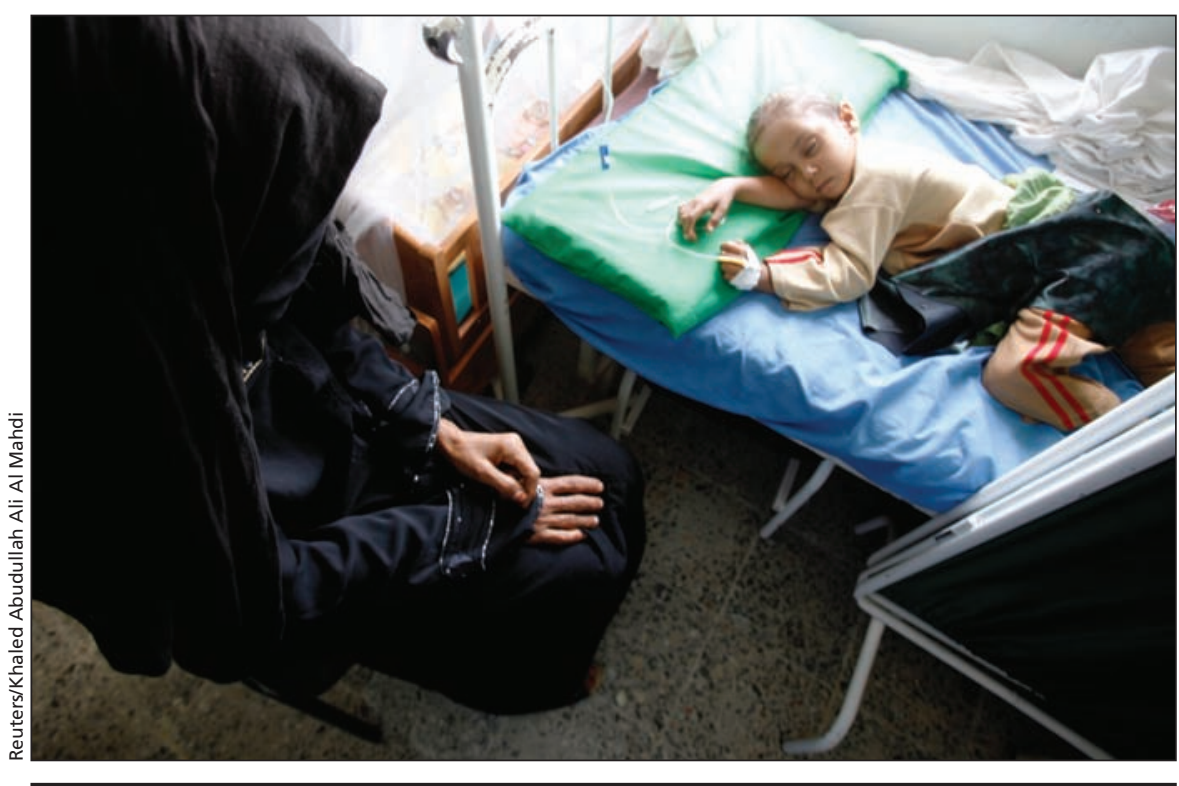

A woman watches over her sick daughter at a health centre on the outskirts of the northwestern Yemeni city of Hajja.

If pledges do surface in Muskoka, host Canada has signalled it wants the monies directed at strengthening health systems in developing nations, a marked departure from previous G8 targeting of major infectious diseases. The new strategy was endorsed at a G8 development ministers' meeting in Halifax, Nova Scotia, earlier this year and continues to be strongly promoted by International Co-operation Minister Bev Oda (CMAJ 2010. DOI:10.1503/ cmaj.109-3250).

Oda told a Toronto audience in June that the era of international health programs designed around "vertical campaigns" focusing on specific diseases is over. The time has come to integrate health programs across the spectrum of diseases and alongside programs tackling nutrition, public hygiene and health worker education, she argues.

That approach is long overdue, says Wim Van Lerberghe, director of the World Health Organization's department for health system governance and service delivery. "It's a necessary condition [for child and maternal health improvement.] Without it your money is wasted. If you want better health outcomes you have to support health systems."

International health organizations appear amenable.

The Global Fund to Fight AIDS, Tuberculosis and Malaria could broaden its mandate to include strengthening health systems if the G8 is willing to replenish the pot, Executive Director Michel Kazatchkine said in June. "Additional funds would allow the Global Fund to accept additional responsibilities," he told CMAJ. "We could substantially reduce child and maternal deaths. We would encourage a comprehensive approach."

Other major aid organizations have equally expansive visions. The Washington, DC-based World Bank, for example, has forged a consensus from more than 80 countries and nongovernmental organizations around nutrition. The plan calls for $\$ 10$ billion focused on nutritional programs as a key plank in improving primary care in the poorest, most disease-ridden nations. 
David Stevenson, director of policy, planning and strategy for the Rome, Italy-based World Food Programme, told a Toronto audience that such a "comprehensive" program is needed, and could be delivered by his organization, which now delivers food aid to 100 million people.

Other supplicants include the Geneva-based Global Alliance for Vaccines and Immunization. "We certainly have expectations," says Geoff Adlide, director of advocacy and public policy. "We have submitted to the Canadian government that immunization ought to be part [of the G8 plan]," he says, adding that the alliance "offers a platform now that is reaching $79 \%$ of children and developing countries."

The alliance has pioneered publicprivate financing mechanisms under which donor commitments are leveraged to raise money on bond markets, exactly the sort of approach G8 finance ministers have advocated, he adds.

Could its mandate be expanded?

"We certainly support an integrated approach," Adlide says. "The health workers who deliver babies also deliver vaccines. It's the same person. If you visit any health centre in a remote area, it's the moms who bring the babies for vaccination. This represents a great opportunity for health systems strengthening."

Picking and choosing amongst the petitioners will not be easy for the G8 leaders and may require change on the part of some international aid groups, maternal and child health scientists say.

"If the Global Fund is going to move into health systems strengthening, they are going to have to shift way from their tradition of not getting involved [with national health policies]," notes Charles Larson, director of the Centre for International Child Health at BC Children's Hospital in Vancouver. "But the Global Fund offers a good model that can be tweaked," provided it is required to report to a fully independent auditor to validate its programs.

Nor should training programs for health workers be overlooked, argue
Larson and Allan Ronald, senior scientific advisor for the Public Health Agency of Canada's national coordinating centre for infectious diseases.

Training investments will yield the largest returns in health outcomes, says Ronald. "By working to strengthen medical schools and their relationships with health ministries, and by strengthening academic and ministerial capacity to lead and achieve the full gradation of care, very substantial gains in outcomes can be forged."

Nalini Singhal, neonatalogist at the University of Calgary in Alberta, concurs. Educating health workers in community and clinical settings will yield the largest child and maternal survival dividends, she says. G8 leaders "seem to be focused on aid being big money. But what we really need to be doing is focusing on strengthening the health programs that countries already have available." - Paul Christopher Webster, Toronto, Ont.

DOI:10.1503/cmaj.109-3300 